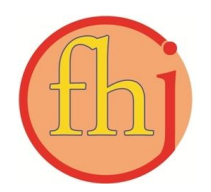

Faletehan Health Journal, 6 (1) (2019) 37-44

www. journal.Ippm-stikesfa.ac.id/ojs/index.php/FHJ

ISSN 2088-673X | e-ISSN 2597-8667

\title{
Determinan Personal Hygiene Pada Anak Usia 9-12 Tahun
}

\author{
Utami Triasmari ${ }^{1}$, Andiko Nugraha Kusuma ${ }^{1 *}$ \\ 1Program Studi Kesehatan M asyarakat, STIKes Faletehan Serang, Indonesia \\ *Corresponding Author: andiko.kusuma@yahoo.com
}

\begin{abstract}
Abstrak
Anak usia sekolah dasar merupakan masa tumbuh kembang yang baik, sehingga diperlukan pengawasan terhadap kesehatannya khususnya personal hygiene. Personal hygiene sangat penting bagi anak karena seringkali anak terkena penyakit akibat tidak memperhatikan personal hygiene. Tujuan penelitian ini adalah untuk mengetahui faktor-faktor yang berhubungan dengan personal hygiene pada anak usia 9-12 tahun di Kelurahan Kalanganyar Wilayah Kerja Puskesmas Pancur tahun 2018. Penelitian ini menggunakan desain Cross Sectional. Populasi penelitian ini adalah semua anak usia 9-12 tahun yang berada di Kampung Kalanganyar dengan jumlah sampel 73 responden yang diambil secara total sampling. Pengumpulan data primer menggunakan kuesioner dan wawancara. Analisis data dilakukan secara univariat dan bivariat menggunakan uji chi square. Hasil penelitian menunjukkan bahwa sebanyak 30,1\% kurang baik dalam melakukan personal hygiene, 38,4\% memiliki pengetahuan kurang, 42,5\% memiliki sikap negatif dan 72,6\% tidak terpapar akses media sosial. Hasil uji hubungan menunjukkan bahwa tidak ada hubungan yang signifikan antara pengetahuan dengan personal hygiene $(\mathrm{Pv}=0,623)$, ada hubungan antara sikap $(\mathrm{Pv}=0,032)$ dan akses media sosial $(\mathrm{Pv}=0,044)$ dengan personal hygiene pada anak usia 9-12 tahun. Diharapkan anak menerapkan pola hidup bersih dan sehat yang baik dan mengulangnya terus menerus.
\end{abstract}

Kata Kunci: Personal Hygiene, Pengetahuan, Sikap

\begin{abstract}
Primary school-age children are good growth periods, children need to be monitored for their health. Personal hygiene is very important for children because the child is affected by the disease because of bad in personal hygiene. The purposes of this research is to find the factors associated with personal hygiene of 9-12 years old children in Kalanganyar Village, Puskesmas Pancur in 2018. The design of this research is cross sectional. The population of this research is all children in 9-12 years who living in Kalanganyar Village with a sample of 73 respondents that has been taken using total sampling. Primary data collection using questionnaire and interview method. Data analysis was done univariat and bivariate. The result obtained $30,1 \%$ less good in personal hygiene, 38,4\% have lack of knowledge, $42,5 \%$ have a negative attitude, and $72,6 \%$ are not exposed to social media access. The result of analysis showed there was no significant correlation between knowledge and personal hygiene $(p=0,623)$, there was significant correlation between attitude $(p=0,032)$ and social media access $(p=0,044)$ with personal hygiene of $9-12$ years children in Kalanganyar Village. The suggestion of this research is are children adopting a good clean and healthy lifestyle and repeating it continuously, and practicing good examples of good health and life behaviors with complete and orderly stages.
\end{abstract}

Keywords: Personal Hygiene, Knowledge, Attitude

\section{Pendahuluan}


Personal hygiene merupakan perawatan diri yang mempengaruhi kesehatan manusia dimana personal hygiene dilakukan sebagai aktifitas kehidupan sehari-hari. Lazimnya personal hygiene pada anak fase usia sekolah 7-12 tahun meliputi kebersihan tangan, kebersihan kuku dan kebersihan baju (Ardhiyarini, 2008). Personal Hygiene sangat penting bagi anak karena seringkali anak terkena penyakit akibat tidak memperhatikan tentang personal hygiene. Pengetahuan personal hygiene harus diberikan sejak dini, tujuannya agar pengetahuan anak tentang kebersihan diri akan lebih matang, sehingga anak akan terbiasa untuk melakukan personal hygiene.

Anak usia Sekolah Dasar (SD) merupakan masa tumbuh kembang yang baik, pada masa ini, anak-anak perlu mendapatkan pengawasan terhadap kesehatannya karena pada usia sekolah, anak-anak mempunyai banyak aktifitas yang seringkali berhubungan langsung dengan lingkungan yang kotor sehingga menyebabkan anak-anak mudah terserang penyakit. Kurangnya pengetahuan dan kesadaran orang tua dalam memperhatikan personal hygiene anak menyebabkan anak juga tidak memperhatikan kebersihan dirinya sendiri, termasuk perawatan kuku pada anak-anak. Meskipun terlihat kecil, tetapi perawatan kuku juga merupakan hal penting yang harus diperhatikan (Wong, 2009).

Personal hygiene pada anak usia sekolah dasar di Indonesia berpotensi menyebabkan masalah kesehatan, seperti infeksi saluran pernapasan, anemia, penyakit kulit, cacingan, dan diare. Anak-anak usia sekolah dasar yang tidak begitu mengerti dengan baik bagaimana menjaga personal hygiene khususnya kebersihan tangan dapat berpotensi menyebabkan terjadinya penyakit cacingan (Rosso \& Arlianti, 2009). Selain kecacingan, penyakit lain yang juga disebabkan karena personal hygiene yang kurang adalah penyakit kulit. Penyakit kulit mudah menginfeksi bila kebiasaan tidak menjaga kebersihan, terutama kebersihan pribadi. Penerapan kebersihan pribadi maka dapat memutuskan mata rantai penularan agent penyebab penyakit kulit dari tempat hidupnya ke host. Penyakit kulit akan lebih mudah menyerang apabila imun seseorang turun (Price \& Wilson, 2006).

Personal hygiene yang kurang pada anakanak juga dapat menyebabkan diare. Anak-anak merupakan golongan umur yang paling menderita karena masih memiliki daya tahan tubuh yang lemah. Diare dapat disebabkan karena infeksi atau non infeksi. Timbulnya penyakit diare disebabkan oleh keadaan lingkungan dan perilaku masyarakat yang tidak menguntungkan. Banyak hal yang dapat mempengaruhi kejadian di suatu wilayah yaitu kuman penyakit yang menyebar melalui mulut, kebersihan lingkungan, umur, letak geografi, dan juga perilaku masing-masing individu (Juli, 2005 dalam Nita, 2016). Berdasarkan data Profil Puskesmas Pancur tahun 2017, jumlah penderita diare di Kelurahan Kalanganyar pada anak usia 514 tahun sebanyak 122 anak. Jumlah penderita penyakit kulit seperti dermatitis di Kelurahan Kalanganyar pada anak usia 5-14 tahun sebanyak 57 anak.

Kondisi personal hygiene pada anak-anak dapat dipengaruhi oleh berbagai faktor, diantaranya adalah pengetahuan, sikap anak-anak terhadap personal hygiene, peran guru di sekolah, peran dan dukungan orang tua, ketersediaan sarana prasarana kebersihan diri dan juga akses terhadap media-media kesehatan. Berbagai penelitian menunjukkan adanya hubungan antara pengetahuan dengan personal hygiene. Penelitian yang dilakukan Prasetyo (2015) didapatkan hasil pengetahuan personal hygiene pada siswa sebagian besar baik sebanyak 49 orang $(65,3 \%)$, dan ada hubungan antara tingkat pengetahuan dengan personal hygiene. Hal ini menunjukkah bahwa pengetahuan responden yang baik mempengaruhi personal hygiene responden (Prasetyo, 2015).

Penelitian Antoni (2013) didapatkan hasil tindakan personal hygiene yang kurang baik lebih banyak terjadi pada responden yang memiliki sikap negatif $(53,3 \%)$ dibandingkan dengan responden yang memiliki sikap positif $(5,6 \%)$, dan ada hubungan antara sikap dengan tindakan personal hygiene di SD Negeri No. 55 Air Pacah Padang (Antoni, 2013). Selain pengetahuan dan sikap yang berhubungan secara signifikan dengan personal hygiene anak pada penelitian sebelumnya, media promosi kesehatan juga diperkirakan menjadi salah satu faktor yang dapat mempengaruhi pengetahuan anak tentang personal hygiene. Menurut Pertiwi dan Annissa (2018) menyebutkan bahwa media promosi kesehatan yang terdapat di lingkungan sekolah dasar tersedia sebanyak $65 \%$ dalam bentuk buku-buku pelajaran dan poster kebersihan yang jumlahnya masih sangat terbatas (Pertiwi, Annissa, 2018). Keterbatasan media promosi kesehatan tersebut dapat berdampak pada tingkat pengetahuan siswa, sehingga perlu adanya 
Faletehan Health Journal, 6 (1) (2019) 37-44

www. journal.Ippm-stikesfa.ac.id/ojs/index.php/FHJ

ISSN 2088-673X | 2597-8667

peningkatan pengetahuan. Peningkatan pengetahuan dapat dilakukan melalui berbagai cara, diantaranya adalah dengan cara edukasi dan sosialisasi baik melalui media cetak maupun non cetak. Saat ini penggunaan media non cetak seperti media sosial dianggap sangat efektif untuk menyampaikan pesan-pesan kesehata. Pada penelitian yang dilakukan Arief dalam Nuryati dan Yanti (2017) menyatakan bahwa media sosial sangat efektif sebagai media edukasi dan sosialisasi kepada masyarakat tentang pentingnya kesehatan secara umum.

Berdasarkan survei pendahuluan, diketahui bahwa penerapan personal hygiene anak usia 9-12 tahun belum optimal. Hasil survei pendahuluan pada 20 anak usia 9-12 tahun di Kelurahan Kalanganyar didapatkan seluruh anak memiliki kuku yang panjang dan tangan yang kotor. Saat diwawancara oleh peneliti, 13 anak menjawab tidak mengetahui akan pentingnya menjaga tangan dan kuku agar tetap bersih, tidak pernah mencuci tangan menggunakan sabun setelah buang air besar dan 5 anak juga mengaku malas mandi. Hasil survei pendahuluan juga diketahui bahwa anak mengatakan tidak tahu cara mencuci tangan yang baik dan benar, 15 anak mengatakan belum memahami bagaimana cara menjaga kebersihan gigi dan mulut. Penelitian ini bertujuan untuk mengetahui determinan personal hygiene pada anak usia 9-12 Tahun di Kp. Kalanganyar Kelurahan Kalanganyar Wilayah Kerja Puskesmas Pancur Kota Serang Tahun 2018.

\section{Metode Penelitian}

Penelitian ini menggunakan metode penelitian analitik dengan pendekatan desain studi cross sectional karena variabel dependen dan variabel independen diukur secara bersamaan (Chandra, 2008). Pada penelitian ini, variabel dependen adalah personal hygiene sedangkan variabel independen adalah pengetahuan, sikap dan akses informasi diukur dalam waktu yang bersamaan. Penelitian ini dilaksanakan di Kp. Kalanganyar Kelurahan Kalanganyar Kecamatan Taktakan Kota Serang. Penelitian ini dilaksanakan pada bulan Juli 2018.

Populasi dalam penelitian ini adalah seluruh anak usia 9-12 tahun yang ada di Kp. Kalanganyar Kelurahan Kalanganyar Wilayah Kerja Puskesmas Pancur Kota Serang. Jumlah populasi seluruhnya 73 anak usia 9-12 tahun. Sampel penelitian ini adalah total sampling. Data penelitian diperoleh dengan cara wawancara menggunakan kuesioner yang telah melalui uji validitas dan realibilitas. Uji validitas pada penelitian ini dilakukan pada 20 anak usia 9-12 tahun yang berada di Lingkungan Kampung Kidang, Sumur pecung, Serang, dengan responden yang digunakan untuk uji coba memiliki ciri-ciri responden dari tempat dimana penelitian itu dilaksanakan. Hasil uji validitas diketahui bahwa dari 23 pertanyaan personal hygiene, 22 pertanyaan pengetahuan, 16 pertanyaan sikap dinyatakan valid dan realibel. Nilai $r$ hitung untuk pertanyaan personal hygiene diperoleh 0,4990,851 , r hitung pertanyaan pengetahuan sebesar 0,497-0,922 lebih besar dari $r$ tabel $(0,444)$, pertanyaan sikap diperoleh $r$ hitung $(0,487-0,860)$ lebih besar dari $r$ tabel, sehingga dapat disimpulkan bahwa 61 item pertanyaan dinyatakan valid, ( $r$ hitung $>\mathrm{r}$ tabel).

\section{Hasil dan Pembahasan}

Personal Hygiene Anak Usia 9-12 Tahun

Berdasarkan hasil penelitian yang dilakukan pada 73 responden maka dapat diperoleh kondisi personal hygiene responden sebagai berikut ini:

Tabel 1. Kondisi Personal Hygiene, Pengetahuan, Sikap dan Akses Media Sosial Responden

\begin{tabular}{lcc}
\hline \multicolumn{1}{c}{ Variabel } & F & $\mathbf{( \% )}$ \\
\hline Personal Hygiene & & \\
$\quad$ Kurang baik & 22 & 30,1 \\
Baik & 51 & 69,9 \\
\hline Pengetahuan & & \\
$\quad$ Kurang baik & 28 & 38,4 \\
Baik & 45 & 61,6 \\
\hline Sikap & & \\
$\quad$ Negatif & 31 & 42,5 \\
$\quad$ Positif & 42 & 57,5 \\
\hline Akses Media Sosial & & \\
$\quad$ Tidak terpapar & 53 & 72,6 \\
$\quad$ terpapar & 20 & 27,4 \\
\hline$\quad$ Jumlah & $\mathbf{7 3}$ & $\mathbf{1 0 0 \%}$ \\
\hline
\end{tabular}

Sumber: Data primer, 2018

Personal hygiene merupakan kebersihan dan kesehatan perseorangan yang bertujuan untuk mencegah timbulnya penyakit pada diri sendiri dan orang lain, baik secara fisik dan psikologis (Silalahi, Putri, 2018). Personal hygiene berasal dari bahasa Yunani yaitu personal yang artinya perorangan dan hygiene berarti sehat. Kebersihan seseorang merupakan suatu tindakan untuk 
memelihara kebersihan dan kesehatan untuk kesejahteraan fisik dan psikis. Berdasarkan tabel 1, diketahui bahwa dari 73 responden yang melakukan personal hygiene kurang baik yaitu sebanyak $22(30,1 \%)$ responden, yang melakukan personal hygiene dengan baik yaitu sebanyak 51 $(69,9 \%)$. Dari hasil personal hygiene ini menunjukkan suatu keadaan tubuh yang bersih dan sehat di Kampung Kalanganyar, dalam arti lain banyak anak yang sudah menerapkan kebersihan perorangan atau personal hygiene, meskipun masih ada yang tidak menerapkannya.

Anak-anak di Kampung Kalanganyar telah melakukan personal hygiene dengan baik, seperti mengganti pakaian dua kali sehari setelah mandi, mencuci pakaian menggunakan detergen dan air bersih, memakai baju yang sudah disetrika, mandi dua kali sehari, mencuci tangan sebelum dan sesudah makan, menggosok gigi setelah makan pagi dan sebelum tidur, untuk anak laki-laki rambut terlihat rapih dan anak perempuan sebagian besar menggunakan kerudung. Baik dan buruknya personal hygiene dapat berpengaruh pada kesehatan anak, oleh karena itu perlu adanya perhatian dari orang tua dan guru di sekolah untuk memberikan informasi mengenai pentingnya personal hygiene, sehingga anak dapat lebih memahami dan merubah perilaku menjaga kebersihan diri sendiri. Personal hygiene anak dapat dipengaruhi oleh beberapa faktor diantaranya pengetahuan, sikap dan akses media.

Pengetahuan dapat diartikan sebagai hasil dari tahu yang terjadi setelah orang melakukan penginderaan melalui panca indera manusia terhadap suatu objek tertentu (Notoatmodjo, 2011). Sebagian besar pengetahuan manusia diperoleh melalui mata dan telinga. Pengetahuan atau kognitif merupakan domain yang sangat penting untuk terbentuknya tindakan seseorang (overt behavior).

Berdasarkan tabel 1, diketahui bahwa dari 73 responden yang memiliki pengetahuan kurang sebanyak $28(38,4 \%)$ responden, yang memiliki pengetahuan baik sebanyak $45 \quad(61,6 \% \%)$ responden. Dari 22 pertanyaan kuesioner penelitian yang dilakukan mengenai pengetahuan pada responden, didapatkan hasil yang menyatakan bahwa masih ada anak yang memiliki pengetahuan kurang pada kategori yang membahas tentang tujuan dari menyikat gigi, cara membersihkan kulit yang benar, warna kuku yang sehat, mencuci rambut yang benar, mandi yang benar, dan mencuci pakaian yang benar.

Hasil penelitian ini menunjukkan bahwa pengetahuan anak tentang personal hygiene sudah cukup baik. Pengetahuan dapat diberikan secara langsung maupun tidak langsung. Cara langsung yaitu dengan cara mengajarkan dan mempraktikkan cara hidup bersih dan sehat, sebagai contoh petugas kesehatan dapat memberikan contoh bagaimana cara menjaga kebersihan pakaian, kulit, rambut, kuku, mulut dan gigi. Secara tidak langsung yaitu bekal ilmu pengetahuan yang diberikan kepada anak oleh orang tua, guru, dan petugas kesehatan. Dengan usaha ini diharapkan dapat meningkatkan pengetahuan anak terhadap kebersihan dirinya.

Sikap adalah perasaan, pikiran, dan kecenderungan seseorang yang akan kurang lebih bersifat permanen mengenai aspek-aspek tertentu dalam lingkungannya (Mubarak, 2011). Sikap merupakan konstelasi komponen-komponen kognitif, afektif dan konatif yang saling berinteraksi dalam memahami, merasakan dan berperilaku terhadap suatu objek (Azwar, 2013).

Berdasarkan tabel 1, diketahui bahwa dari 73 responden yang memiliki sikap negatif sebanyak $31(42,5 \%)$ responden, yang memiliki sikap positif sebanyak $42(57,5 \%)$ responden. Dari 16 pertanyaan kuesioner yang dilakukan mengenai sikap responden terhadap personal hygiene, didapatkan hasil yang menyatakan bahwa masih ada anak yang menjawab setuju pada pernyataan memakai baju tanpa perlu disetrika, mandi tidak perlu menggunakan sabun, jika sesudah berolahraga tidak perlu mandi, masih ada anak yang menjawab tidak setuju pada pernyataan mengganti pakaian dua kali sehari, pernyataan tersebut seharusnya tidak boleh dilakukan karena hal ini menjadi salah satu sikap yang negatif dan perlu diperhatikan agar tidak menimbulkan penyakit kulit contohnya gatal-gatal, dermatitis, dan sebagainya. Dari hasil penelitian ini dapat dilihat dengan sikap anak tentang personal hygiene yang memiliki sikap positif, hal ini sejalan dengan pengetahuan anak yang cukup tinggi tentang personal hygiene. Hal ini menunjukkan bahwa perlunya sikap positif dan penyadaran pada orang tua dan guru mengenai sikap anak terhadap personal hygiene agar anak dapat memperbaiki sikap kearah yang lebih positif terhadap kebersihan diri. 
Faletehan Health Journal, 6 (1) (2019) 37-44

www. journal.Ippm-stikesfa.ac.id/ojs/index.php/FHJ

ISSN 2088-673X | 2597-8667

Menurut Kamus Bahasa Indonesia, media adalah alat, sarana komunikasi, perantara atau penghubung. Sosial artinya berkenaan dengan masyarakat atau suka memperhatikan kepentingan umum. Dari sisi bahasa, media sosial dapat dimaknai sebagai sarana yang menghubungkan masyarakat untuk berkomunikasi dan berbagi. Media sosial merupakan wadah untuk bersosialisasi dengan menggunakan teknologi berbasis web untuk menyebarluaskan secara pengetahuan dan informasi secara cepat kepada seluruh pengguna internet di dunia.

Berdasarkan hasil penelitian pada tabel 1, diketahui bahwa dari 73 responden yang terpapar akses media sosial sebanyak $20 \quad(27,4 \%)$ responden. Hasil penelitian juga menunjukkan bahwa anak yang mempunyai akun facebook sebanyak $17,8 \%$ responden. Seharusnya responden pada usia 9 - 12 tahun tidak memiliki akun di media sosial karena responden belum memiliki otoritas khusus terhadap penggunaan media sosial. Kepemilikan akun di media sosial juga dapat disebabkan karena domisi demografi. Sebagian besar responden berdomisili di wilayah tempat tinggal yang terletak di wilayah pedesaan, sehingga masih banyak anak yang tidak memiliki media sosial. Rata-rata anak usia sekolah dasar masih berfokus pada kegiatan bermain di luar rumah seperti bermain bola, dan lain sebagainya. Anak yang mempunyai akun media sosial biasa mengakses facebook 2-3 hari sekali, dan yang terpapar informasi mengenai personal hygiene dari akun media sosial sebanyak $(5,5 \%)$ responden. Selain itu, ada faktor lain yang mempengaruhi anak mengetahui informasi mengenai personal hygiene bisa dari peran orang tua, guru, petugas kesehatan. Jadi, bukan dari media sosial saja anak tersebut terpapar personal hygiene.

\section{Analisis Bivariat \\ Hubungan Antara Pengetahuan dengan Personal Hygiene Anak Usia 9-12 Tahun}

Hubungan antara pengetahuan responden dengan Personal Hygiene di Kelurahan Kalanganyar, dilakukan uji Chi Square, dengan variabel pengetahuan yang membedakan menjadi 2 kategori yaitu kurang dan baik. Hasil uji Chi Square antara pengetahuan dengan personal hygiene di Kelurahan Kalanganyar dapat dilihat melalui tabel berikut:

Berdasarkan tabel 2, dapat diketahui dari 28 responden yang memiliki pengetahuan kurang, terdapat $21(75,0 \%)$ responden yang melakukan personal hygiene dengan baik, sedangkan dari 45 $(100 \%)$ responden yang memiliki pengetahuan baik, terdapat $30(66,7 \%)$ responden yang melakukan personal hygiene dengan baik. Hasil uji statistik dengan menggunakan uji chi square diperoleh nilai $\mathrm{P}=0,623$ berarti nilai $\mathrm{Pv}<\alpha(0,05)$ maka dapat disimpulkan secara statistik pada $\alpha 5 \%$ tidak ada hubungan yang signifikan antara pengetahuan dengan personal hygiene. Hasil penelitian tidak ada hubungan secara signifikan sehingga nilai OR tidak ditampilkan.

Pengetahuan adalah suatu proses penggunaan panca indera yang dilakukan seseorang terhadap objek tertentu sehingga dapat menghasilkan pengetahuan dan keterampilan (Duran dan Barlas, 2016). Menurut Maulana (2009) pengetahuan merupakan informasi yang diperoleh seseorang dan akan diproses sehingga menghasilkan pengetahuan, semakin sering seseorang mendapatkan informasi maka akan semakin meningkat pengetahuannya dan juga mempengaruhi sikap dan perilakunya (Maulana, 2009).

Tabel 2. Hubungan Pengetahuan dengan Personal Hygiene

\begin{tabular}{lccccccc}
\hline \multirow{3}{*}{ Pengetahuan } & \multicolumn{8}{c}{ Personal Hygiene } \\
\cline { 2 - 8 } & \multicolumn{1}{c}{ Kurang Baik } & \multicolumn{2}{c}{ Baik } & \multicolumn{3}{c}{ Jumlah } & \multirow{2}{*}{ P value } \\
\cline { 2 - 8 } & $\mathbf{n}$ & $\mathbf{\%}$ & $\mathbf{n}$ & $\mathbf{\%}$ & $\mathbf{n}$ & \% & \\
\hline Kurang & 7 & 25 & 21 & 75 & 28 & 100 & \multirow{2}{*}{0,623} \\
Baik & 15 & 33,3 & 30 & 66,7 & 45 & 100 & \\
\hline Jumlah & 22 & 30,1 & 51 & 69,9 & 73 & 100 & \\
\hline
\end{tabular}

Sumber: Data primer, 2018

Hasil analisis hubungan antara pengetahuan dengan personal hygiene diperoleh hasil bahwa yang memiliki personal hygiene kurang baik lebih banyak pada responden yang memiliki 
pengetahuan baik sebanyak 15 (33,3\%) dibandingkan dengan responden yang memiliki pengetahuan kurang sebanyak 7 (25,0\%). Hasil ini tidak sejalan dengan penelitian Prasetyo (2015) yang menyatakan bahwa adanya hubungan tingkat pengetahuan dengan personal hygiene pada siswa di SDN Panjang Wetan IV Kecamatan Pekalongan utara kota Pekalongan. Hal ini menunjukkan bahwa adanya faktor lain yang mempengaruhi personal hygiene anak usia sekolah, contohnya dari faktor pendukung yaitu ketersediaan fasilitas/sarana, faktor penguat yaitu orang tua atau keluarga, guru, tokoh masyarakat, tokoh agama dan petugas kesehatan.

Hal ini menunjukkan bahwa jika pengetahuan anak usia sekolah semakin baik, maka personal hygiene mereka akan semakin baik pula, ditandai dengan banyaknya anak yang mengerti dan tahu mengenai hal-hal yang berhubungan dengan personal hygiene serta pentingnya menjaga kebersihan diri. Responden yang pengetahuannya baik tidak menjamin akan mempunyai sikap dan perilaku yang positif terhadap personal hygiene, karena responden dalam menentukan sikap dan perilaku yang utuh selain ditentukan oleh pengetahuan, dipengaruhi juga oleh pikiran, keyakinan, dan emosi yang memegang peranan penting. Faktor lain juga seperti usia, pendidikan, minat, pengalaman, informasi dan kebudayaan lingkungan sekitar yang menjadi alasan responden yang pengetahuan baik belum menerapkan personal hygiene dengan baik dan benar.

\section{Hubungan Antara Sikap Dengan Personal Hygiene Anak Usia 9-12 Tahun}

Berdasarkan tabel 3, dapat diketahui dari 31 (100\%) responden yang memiliki sikap negatif, terdapat $17(54,8 \%)$ responden yang melakukan personal hygiene dengan baik, sedangkan dari 42 (100\%) responden yang memiliki sikap positif, terdapat $34(85,0 \%)$ responden yang melakukan personal hygiene dengan baik. Hasil uji statistik dengan menggunakan uji chi square diperoleh nilai $\mathrm{P}=0,032$ berarti $\mathrm{Pv}<\alpha \quad(0,05)$ maka dapat disimpulkan secara statistik pada $\alpha 5 \%$ ada hubungan yang signifikan antara sikap dengan personal hygiene. Dari hasil analisis diperoleh pula nilai $\mathrm{OR}=3,500$ artinya anak dengan sikap negatif mempunyai risiko 3,500 kali untuk memiliki personal hygiene yang kurang dibanding anak dengan sikap positif.

Menurut Notoatmodjo (2012) sikap adalah respon yang dilakukan secara tertutup yang ada pada seseorang terhadap stimulus atau obyek tertentu yang sudah melibatkan faktor pendapat dan emosi yang bersangkutan (senang-tidak senang, setuju-tidak setuju, baik-tidak baik, dan sebagainya). fungsi sikap belum merupakan suatu tindakan (reaksi terbuka) atau suatu aktifitas, akan tetapi merupakan predisposisi perilaku (tindakan) atau reaksi tertutup.

Tabel 3. Hubungan Sikap dengan Personal Hygiene

\begin{tabular}{|c|c|c|c|c|c|c|c|c|}
\hline \multirow{3}{*}{ Sikap } & \multicolumn{8}{|c|}{ Personal Hygiene } \\
\hline & \multicolumn{2}{|c|}{ Kurang Baik } & \multicolumn{2}{|c|}{ Baik } & \multicolumn{2}{|c|}{ Jumlah } & \multirow{2}{*}{ P value } & \multirow{2}{*}{ OR } \\
\hline & $\mathbf{n}$ & $\%$ & $\mathbf{n}$ & $\%$ & $\mathbf{n}$ & $\%$ & & \\
\hline Negatif & 14 & 45,2 & 17 & 54,8 & 31 & 100 & & \\
\hline Positif & 8 & 19,0 & 34 & 81,0 & 42 & 100 & 0,032 & 3,500 \\
\hline Jumlah & 22 & 30,1 & 51 & 69,9 & 73 & 100 & & \\
\hline
\end{tabular}

Tabel 4. Hubungan Akses Media Sosial dengan Personal Hygiene

\begin{tabular}{|c|c|c|c|c|c|c|c|c|}
\hline \multirow{3}{*}{$\begin{array}{l}\text { Akses Media } \\
\text { Sosial }\end{array}$} & \multicolumn{8}{|c|}{ Personal Hygiene } \\
\hline & \multicolumn{2}{|c|}{ Kurang Baik } & \multicolumn{2}{|c|}{ Baik } & \multicolumn{2}{|c|}{ Jumlah } & \multirow{2}{*}{ P value } & \multirow{2}{*}{ OR } \\
\hline & n & $\%$ & $\mathbf{n}$ & $\%$ & $\mathbf{n}$ & $\%$ & & \\
\hline Tidak Terpapar & 20 & 37,7 & 33 & 62,3 & 53 & 100 & & \\
\hline Terpapar & 2 & 10,0 & 18 & 90,0 & 20 & 100 & 0,044 & 5,455 \\
\hline Jumlah & 22 & 30,1 & 51 & 69,9 & 73 & 100 & & \\
\hline
\end{tabular}

Sumber: Data primer, 2018 


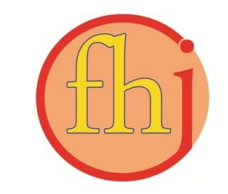

Hasil ini sejalan dengan penelitian Antoni (2013) yang menyatakan bahwa ada hubungan antara sikap dengan tindakan personal hygiene di SD Negeri No. 55 Air Pacah Padang. Sikap memiliki hubungan terhadap tindakan personal hygiene karena jika sikap negatif maka tindakan akan negatif walaupun memiliki pengetahuan yang tinggi. Begitupun dengan sikap yang positif akan mendorong anak untuk melakukan tindakan personal hygiene yang baik dengan dilatar belakangi pengetahuan yang tinggi. Oleh karena itu pengetahuan dan sikap harus sejalan (Antoni, 2013).

Sikap yang masih negatif dengan personal hygiene pada anak usia 9-12 tahun dipengaruhi oleh penerimaan stimulus yang diberikan dan tanggapannya masih tidak peduli sehingga untuk membahas tentang personal hygiene dengan teman ataupun orang lain dan bahkan mengajak atau mempengaruhi untuk orang lain merespon masih kurang. Dalam hal ini dapat disimpulkan bahwa, dengan pengetahuan yang baik akan berbanding lurus dengan sikap seseorang yang baik pula, dimana sikap seseorang dapat diperoleh melalui pengalaman dan merupakan hasil pemikiran individu terhadap orang, tempat, hal atau peristiwa.

\section{Hubungan Antara Akses Media Sosial dengan Personal Hygiene Anak Usia 9-12 Tahun}

Berdasarkan tabel 4, dapat diketahui dari 53 (100\%) responden yang tidak terpapar akses media sosial, terdapat $33(62,3 \%)$ responden yang melakukan personal hygiene dengan baik, sedangkan dari $20(100 \%)$ responden yang terpapar akses media sosial, terdapat $18(90,0 \%)$ responden yang melakukan personal hygiene dengan baik. Hasil uji statistik dengan menggunakan uji chi square diperoleh nilai $\mathrm{P}=0,044$ berarti $\mathrm{Pv}<\alpha(0,05)$ maka dapat disimpulkan secara statistik pada $\alpha 5 \%$ ada hubungan yang signifikan antara akses media sosial dengan personal hygiene. Dari hasil analisis diperoleh pula nilai $\mathrm{OR}=5,455$ artinya anak yang tidak terpapar akses media sosial mempunyai resiko 5,455 kali untuk memiliki personal hygiene yang kurang dibanding anak yang terpapar akses media sosial.

Media sosial adalah sebuah media daring, dimana para pengunanya bisa dengan mudah berinteraksi, berbagi berbagai informasi. Kaplan dan haenlein (2010) mendefinisikan media sosial sebagai sebuah kelompok aplikasi berbasis internet. Menurut Juliasih dalam Kristanto (2011) media sosial adalah media yang sering disebut sebagai media online dimana dapat mewakili para penggunanya untuk saling berinteraksi dengan sesamanya di dunia luar baik yang dikenal maupun tidak.

Hal ini sejalan dengan penelitian Arief dalam Nuryati dan Yanti (2017) yang menyatakan bahwa media sosial sangat efektif sebagai media edukasi dan sosialisasi kepada masyarakat tentang pentingnya kesehatan secara umum dan penelitian Gafar (2014) menyatakan bahwa terdapat pengaruh pemberian edukasi kesehatan melalui facebook terhadap pengetahuan tentang kesehatan. Hal ini dapat disimpulkan bahwa memang penggunaan media sosial sebagai media edukasi tentang personal hygiene sangat efektif, sehingga diharapkan dengan meningkatnya pengetahuan seseorang akan meningkat juga sikapnya terhadap personal hygiene. Selain itu, ada faktor lain yang mempengaruhi responden personal hygienenya baik tetapi tidak terpapar akses media sosial dikarenakan informasi yang mereka dapat tidak hanya dari media sosial saja, tetapi juga dari media televisi, buku, majalah, dll. Hal ini sesuai dengan hasil penelitian Pertiwi dan Annissa yang menyebutkan bahwa media yang paling sering dibaca buku sebanyak 67,7\% (Pertiwi dan Annissa, 2018).

Media sosial dapat digunakan untuk bertanya terkait materi pelajaran sekolah, serta dapat pula digunakan untuk berdiskusi antar anak dengan menggunakan layanan grup yang disediakan media sosial seperti BBM dan Whatsapp. Jika anak mampu menggunakan layanan media sosial untuk hal-hal positif, maka hubungan antar teman sebaya akan semakin erat. Sikap saling tolong menolong juga akan tercipta karena anak saling membantu jika ada teman yang kesusahan.

\section{Simpulan}

Sikap dan akses media sosial berhubungan dengan personal hygiene pada anak usia 9-12 tahun. Anak usia $9-12$ tahun yang terpapar media sosial mempunyai proporsi yang lebih banyak dalam melakukan personal hygiene dibandingkan dengan anak yang tidak terpapar.

\author{
Referensi \\ Antoni, A. (2013). Analisis Pengetahuan dan Sikap \\ Murid SD Tentang Kebersihan Diri di SD
}


Negeri No. 55 Air Pacah Padang Tahun 2013. Padang: Jurnal Kesehatan.

Ardhiyarini. (2008). Faktor - faktor yang mempengaruhi personal hygiene anak usia sekolah di SD Negeri Pleretlor Kecamatan Panjatan Kabupaten Kulon Progo. Universitas Muhammadiyah Yogyakarta.

Azwar, S. (2013). Sikap Manusia Teori dan Pengukurannya. Yogyakarta: Pustaka Pelajar.

Chandra, B. (2008). Metodologi Penelitian Kedokteran. Jakarta: EGC.

Duran, S., Barlas, G. Ü. (2016). Effectiveness of psychoeducation intervention on subjective well being and self compassion of individuals with mental disabilities, 4(1), 181-188.

Gafar, G. (2014). Pengaruh Pemberian Promosi Kesehatan Melalui Media

Sosial Facebook Terhadap Pengetahuan Tentang Kesehatan Di Universitas Muhammadiyah Yogyakarta. Karya Tulis Ilmiah Strata Satu. Universitas Muhammadiyah Yogyakarta.

Kaplan. Andreas, M. Michael Haenlein (2010) Users of the world, unite! The challenges and opportunities of Social Media. Business Horizons

Nita, A. N. (2016). Hubungan Antara Personal Hygiene dengan Kejadian Diare Pada Siswa SDN 05 Batursari Mranggen. Universitas Dian Nuswantoro.
Notoatmodjo, S. (2011). Kesehatan Masyarakat Ilmu dan Seni. Jakarta : Rineka Cipta.

Notoatmodjo, S. (2012). Metodologi Penelitian Kesehatan. Jakarta: Rineka Cipta.

Nuryati, S., Yanti. D. Risna. (2017). Efektifitas Penggunaan Media Sosial Terhadap Peningkatan Pengetahuan Perawatan Nifas dan Kepatuhan Kunjungan Ulang Pada Ibu Nifas di Kota Bogor. Jurnal Poltekkes Kemenkes Bandung: Bandung.

Pertiwi, Wiwik Eko. Annissa. (2018) Ketersediaan Media Promosi Kesehatan. Laporan Penelitian. STIKes Faletehan Serang.

Prasetyo, D.A. (2015). Hubungan Tingkat Pengetahuan dan Dukungan Keluarga dengan Personal Hygiene Pada Siswa di SDN Panjang Wetan IV Kecamatan Pekalongan Utara Kota Pekalongan. Pekalongan: Jurnal Kesehatan.

Price, S. A. dan Wilson, L. M. (2006). Patofisiologi: Konsep Klinis Proses-Proses Penyakit, Edisi 6, Volume 1. Jakarta: EGC.

Silalahi, Verarica.Putri, Mahaji, Ronasari. (2018). Personal Hygiene pada Anak SD Negeri Merjosari 3. Jurnal Akses Pengabdian Indonesia. Vol.2, Edisi 2, hal. 15-23, tahun 2018.

Wong, D. (2009). Keperawatan Pediatrik. Jakarta: EGC 